\title{
Discussion on the Development and Application of Electrical Automation in the New Era
}

\author{
Yuhan Cao
}

North China Electric Power University, Baoding, Hebei, 071003

Keywords: electrical automation; new era; development and application

\begin{abstract}
As China's economy continues to develop, in the new era of the new economy, China faces more than just economic transformation, but also changes in economic structure. In the process of economic development, electrical automation technology has greatly promoted the domestic industrial development level and the transformation of the socialist economic market system. To this end, with the further development of science and technology in China and the improvement of scientific development level, the technology of electrical automation has also been widely promoted in practical applications, which itself plays a very important role in industrial development and the reconstruction of social and economic structure. But what follows is that the technology of electrical automation will become more complicated with the development of science.
\end{abstract}

\section{Introduction}

Electrical automation technology itself as a new development of science and technology in China, this is an inevitable trend in the new era to better help the social economy and industrial development, but also the inevitable outcome of science and technology in the process of upgrading . To this end, in order to facilitate economic development, the development platform of electrical automation itself is gradually expanding, and its technology has been greatly improved and better improved. From the current development point of view, we can know that this technology has been widely used in all walks of life in China, and has achieved good results in terms of practical application results, not only effectively enhancing the competition of enterprises in the social market. Force also directly meets the development needs of the people in daily life and production [1].

\section{Problems in the development of electrical automation technology}

With the development of the economy, science and technology are increasingly updated. In the actual work and life, as science and technology and electrical automation technology provide more and more convenience for life, people are paying more and more attention to and develop electrical automation technology. From the current application situation, we can know that although the current electrical automation technology has a relatively broad development prospect in the process of practical application, in the actual development process, due to the environmental and economic development of different regions. The situation, as well as the operational problems of the staff in the actual work, still have certain problems. These problems have a serious impact on the development of electrical automation technology. The summary can be divided into the following points:

Due to the large land area of our country, different provinces have different economic developments and average academic qualifications. For this reason, each enterprise in the market is in the process of development and the level of professional technicians in the enterprise. They are all different. For this reason, in the actual work of electrical automation technology, the staff in different regions can only design a electrical automation product according to their own knowledge and their own experience. However, this has led to the direct limitation of the development of the level of electrical automation technology in the process of actual work, and directly led to the 
failure of electrical automation technology to be implemented in accordance with uniform standards in China, if not in accordance with uniform standards. Execution, it is not only to increase the difficulty of management in the process of management, but also to the long-term development of the company in the market [2].

In the process of actual work, the quality of electrical automation engineering is judged. It is often determined according to the results shown in the test report. Most of the electrical automation projects in China are rarely followed by relevant professionals. The quality of the field is investigated on the ground. The emergence of this problem has caused loopholes to a certain extent. Many construction companies use relatively cheap materials in order to be able to earn more profits in actual construction, or they are not strictly regulated during construction. After the modification of the test report, the appearance of these things will leave serious safety hazards in the process of actual use of the electrical automation project in the future, so that not only does the work efficiency of the project itself not improve in the actual work process, but also damage The reputation of electrical automation engineering and the reputation of the company responsible for the engineering company. At this stage, the problem of lax supervision of engineering is very frequent in China[3].

\section{How to solve the problems in the development of electrical automation technology}

From the perspective of the trend and situation of social and economic development at the present stage, the main driving force in the process of economic development is electrical automation technology, which effectively promotes China's economic development. Although electrical automation technology still has certain deficiencies in the current development process, as long as the problems can be found in time, and the electrical automation technology can be improved and improved according to the actual situation, it can help the electrical automation technology to achieve better development prospects.

Different from other technologies, in the process of application and analysis of electrical automation technology, its requirements must be professional and technical as a user. Therefore, in the actual work process, as a manager in the enterprise, it must be done. Constantly strengthening and nurturing the existing professionals in the enterprise, the professional number of electrical automation technology is extremely crucial for the development and use of electrical automation technology in enterprises. Especially at this stage, the level of science and technology has been in the era of rapid development. Science and technology are the primary productive forces. Without science and technology, there is no way for the country to gain a foothold in the world. There is no way for enterprises to improve their competitiveness in the market. For this reason, the professionalism of the electrical automation technicians in the enterprise is particularly important. At the same time, in the construction process of electrical engineering, enterprises need more professional talents, and the competition of people and the cultivation of talents are more and more important in the market. As a company that wants to develop in the market, if we want to constantly improve our own competitiveness, if we want to keep up with the development of the times, we must do it in a timely manner and introduce advanced equipment at home and abroad according to actual conditions. Advanced electrical automation technology to enhance its own advantages. As the manager of the enterprise, it is necessary to continuously increase the training of the internal professional staff of the company to help the company's electrical automation technology staff to change to a more specialized direction, not only to master the electrical in real time. The development of automation technology can also continuously improve its professional ability and professional business. It can also carry out academic and work cooperation and exchanges with the staff of the same industry on a regular basis, and increase the research intensity of electrical automation technology in the whole industry. The enterprises in the market can be improved as a whole in the process of development. Therefore, in the current development of China's electrical automation technology industry, the professional training of talents has become an irreversible development trend [4].

At the present stage, one of the main problems in the process of applying electrical automation technology in China is that the electrical automation implementation standards are not uniform. 
Many enterprises developing in the market do not construct a unified electrical automation system platform. There have been many problems in the process of technology. There is no way to solve these problems in time and cause some delay. To solve this problem, we need to build a unified electrical automation system platform in the enterprise, and put this in the process of doing business. The most important development work. In addition to the need to train the relevant professional and technical knowledge of the electrical automation technology staff in the enterprise, in the process of actual work, the managers in the enterprise still need to do is to combine the development characteristics of the actual industry with the users themselves. The requirements are compared, and then the specific design of the automation process, after the design of the first link is completed, it is necessary to prepare the relevant alternatives. After ensuring that the designed solution itself is feasible, the company needs to submit this solution to a professional electrical automation technician for safety level assessment to improve the operability of the program in the actual work process. This is very important for building a unified electrical automation system platform in real life. Constructing a unified electrical automation system platform not only reduces the cost of electrical engineering in the process of development, but also maximizes the investment capital required by the enterprise in the process of production, and can also improve electrical engineering. The efficiency of the work and the quality of the work, to maximize the economic benefits of the company in the development process [5].

Only by ensuring the safety of a technology in actual use can this technology be better applied in all walks of life. In order to develop electrical automation technology, it is necessary to continuously improve the versatility of electrical automation technology itself. And security. The general system of information itself gives the best resource allocation in the process of development of electrical automation technology. The general system of information utilization can help the users of electrical automation technology to better operate, find problems and solve problems in time. For this reason, in the process of continuously strengthening the electrical automation technology, as a related enterprise, it is also necessary to improve and pay attention to the versatility and safety of the electrical system. This not only helps real-time monitoring and management of all aspects of electrical automation, but also helps departments in the enterprise to use information and data to efficiently and quickly share information at the fastest speed. In the process of perfecting automation technology, it is also necessary to use electrical automation technology according to its actual situation. The general system of information can strengthen the safety and timeliness of various departments in the process of information dissemination, and help enterprises continuously Improve work efficiency and improve on the basis of the original. At this stage, the use of information exchange equipment is also more secure, preventing artificial changes to the data, greatly reducing the occurrence of security risks in the work process, and promoting the long-term development of enterprises in the market.

\section{Discussion on the application of electrical automation technology in the new era}

Water resources have always been an indispensable resource in China's economic development and social development. At this stage, the content of groundwater is gradually decreasing. If the water resources are better used in actual production and life, it has always been It is the focus of thinking in relevant departments of China. To this end, the application of electrical automation technology in the management and use of water plants can not only effectively improve the efficiency of its work in the actual work process, but also achieve real energy conservation and sustainable development. Electrical automation technology can also be used to continuously strengthen the management and management of water plants by managers, and to increase the scope of supervision and control of water plants in the actual work process. At the same time, in the process of actual work, the rational use of electrical automation equipment can also make the management mode of the water plant more modernized, with network development in line with the new situation, and improve its own advantages.

In China's ports, it has always been an important place for economic exchanges. Since the reform and opening up, the role of the port in the process of real economic development has become more 
and more obvious. To ensure that the social economy can develop more smoothly, it must be done. It is to constantly carry out technological innovations. In the new era, China has always wanted to increase the speed of development of ports at the present stage, improve the efficiency of port utilization, and maximize the use of ports. To achieve this goal, it is necessary to use electrical automation technology in port management. The use of electrical automation technology can enable the port to continuously improve its own work efficiency in the most basic daily work. While successfully reducing the cost of human use, it also accelerates the further development of China's ports.

Electricity has always made a great contribution to the country's economic development. In the process of economic development, it must rely on electricity. At this stage, all walks of life and work are inseparable from electricity. This resource is not only a renewable resource but also a clean energy source. It plays a very important role in global warming today. It is necessary to constantly develop it. When the electrical automation technology is applied in practice, it is mainly applied to electric power. The application of electrical automation technology in electric power can provide the most important help for the development of electrical automation. Utilizing the electrical automation technology used in China at this stage, it can be known that the electrical automation technology in the power system can be combined with the overvoltage and overcurrent protection technology, the current detection technology and the like, and the new power electronic switch obtained. It has helped the power industry to develop better, and at the same time, it has made great breakthroughs in China's electrical automation system technology.

\section{Conclusion}

According to the above summary, electrical automation in modern times, both for the modern enterprise developed in the market, or for the daily production and development of the people, the development of electrical automation technology and its engineering is the life of people. Closely related. To this end, we want to make the economy more stable, we must do more to pay more attention to electrical automation technology. At the present stage, in the process of electrical automation development, there are some problems that need to be corrected according to the actual situation, and strive to make up for each other's strengths, so that they can better play their own advantages in the work, and put the electrical automation technology into More application areas to promote the growth of China's economic efficiency.

\section{References}

[1] Wen-Jing M A. Discussion on application of electrical automation in electric power system [J]. Heilongjiang Science, 2016.

[2] Yi J, Center M I. The Discussion of Application of Electrical Automation Technology in Chemical Production and Its Development Tendency [J]. Guangdong Chemical Industry, 2016.

[3] Zhang Z H, Rong-Jie L I. Discussion on the Application of Electrical Automation in Electrical Engineering [J]. Construction \& Design for Engineering, 2017.

[4] Zhang Z H, Rong-Jie L I. Discussion on the Application of Electrical Automation in Electrical Engineering [J]. Construction \& Design for Engineering, 2017.

[5] Zhao Y, Zhao G, Huang S W. Discussion on professional design of application-oriented electrical engineering and automation[J]. Laboratory Science, 2011. 